\title{
NuPE/UFPR - Núcleo de Políticas \\ Educacionais: criação, características e desafios
}

\author{
NuPE/UFPR: Research Center of Education Policies: \\ creation, characteristics and challenges
}

Taís Moura Tavares

\section{Resumo:}

O artigo apresenta a constituição do Núcleo de Políticas Educacionais da Universidade Federal do Paraná - NuPE/UFPR, e foi escrito no semestre de comemoração dos seus dez anos de fundação (outubro de 2012). O documento expressa a trajetória diversa e ampliada que vem tomando, desde então, o grupo de pesquisa, demonstrando como o núcleo se insere no movimento de constituição e definição de um campo recente de pesquisa educacional: o de políticas. O texto, ao final, ressalta que embora o NUPE esteja consolidado como um grupo de pesquisa que por uma década tem mantido e ampliado sua produção, em termos de resultados de pesquisa, sua divulgação e formação de novos pesquisadores, o adensamento teórico e metodológico desse trabalho é, ainda, um desafio que se impõe.

Palavras-chave: Políticas Educacionais; Pesquisa; NUPE/UFPR.

\begin{abstract}
:
The paper presents the creation of the Research Center of Education Policy at Federal University of Paraná - NuPE/UFPR, and was written in commemoration of its ten years of foundation (October 2012). The text expresses the diverse and expanded trajectory that it has taken since then, demonstrating how the research center is involved in the movement of creation and definition of a new field of educational research: education policies. The article at the end, points out that although NuPE is established as a research group which for a decade has maintained and expanded its production, in terms of research results, their dissemination and training of new researchers, the methodological and theoretical densification of its work is still a important and hard challenge.
\end{abstract}

Keywords: Education policies; Research; NUPE/UFPR. 
O objetivo do presente artigo não é fazer uma retrospectiva histórica, mas refletir sobre a trajetória do NuPE/UFPR - Núcleo de Políticas Educacionais do Setor de Educação da Universidade Federal do Paraná (UFPR), e identificar as marcas do trabalho realizado ressaltando os ganhos e as realizações no âmbito desse esforço de permanecermos trabalhando em conjunto, com o intuito de superar o habitus, ainda forte na universidade brasileira, de primar pelo trabalho individual e isolado no campo de investigação, do ensino e da extensão.

Assim sendo, iniciaremos pelas palavras de Bernadete Gatti, autora que enfatiza o significado e a importância da criação de grupos de pesquisa na área da educação:

0 pesquisador não trabalha sozinho, nem produz sozinho. A intercomunicação com pares, o trabalho em equipe, as redes de trocas de ideias e disseminação de propostas e achados de investigação, os grupos de referência temática, constituem hoje uma condição essencial à realização de investigações científicas e ao avanço dos conhecimentos (2005, p.124).

O NuPE nasceu em 2002 a partir da iniciativa de um grupo de professores que vinham de uma experiência de trabalho conjunto em pesquisa sobre financiamento da educação. Reunia professores com mais conhecimento em pesquisa, doutores que atuavam no Programa de Pós-graduação em Educação e pesquisadores em formação. Embora já houvesse pesquisas constituídas por grupos de professores e outras iniciativas no Setor de Educação da Universidade Federal do Paraná para institucionalizar grupos de pesquisa (por exemplo, o Núcleo de Mudanças Tecnológicas e Educação do Trabalhador), sua criação marca, no campo das Políticas Educacionais, a superação da prática de pesquisa estritamente individual, dominante naquele período e, quiçá, ainda hoje.

Desde as primeiras discussões, o Núcleo visava à elaboração de conhecimento, por meio da pesquisa e da socialização, sob as mais diversas formas. Essa tem sido uma das marca do trabalho desenvolvido ao longo desses 10 anos de existência.

\section{Panorama das atividades:}

- Um levantamento inicial das pesquisas realizadas em grupo indica as principais temáticas da investigação realizada pelo NuPE:

- Financiamento da educação na Região Metropolitana de Curitiba;

- Levantamento do custo aluno em escolas públicas com condições de qualidade no estado do Paraná;

- A implantação e os impactos do FUNDEF no estado do Paraná;

- Trabalho docente na educação básica;

- Políticas educacionais e qualidade de ensino: as relações entre o investimento financeiro em educação, as condições de qualidade, o perfil da demanda educacional e o desempenho estudantil no estado do Paraná.

- E estão em andamento:

- Remuneração de professores de escolas públicas de educação básica: configurações, impactos, impasses e perspectivas;

- Qualidade no ensino fundamental: uma leitura das condições de efetividade dos sistemas estaduais e municipais de ensino a partir de indicadores de financiamento, condições de oferta e resultados escolares;

- Análise comparada das políticas educacionais brasileiras e chilenas: avaliação da demanda, do perfil de financiamento, das condições de qualidade e dos resultados da educação no período pós-reformas educacionais.

Além dessas, estão vinculadas ao NuPE pesquisas individuais de professores, mestrandos e doutorandos. 
Do ponto de vista da socialização dos resultados, o Núcleo interage com a graduação, nos cursos de licenciatura, com disciplinas que tem como temáticas a gestão, o financiamento e as políticas educacionais. Já na pós-graduação em Educação, a oferta em disciplinas para Mestrado e para Doutorado que participam em linhas de Pesquisa em Políticas Educacionais, além das ofertadas nos cursos de especialização em Políticas Educacionais. Por meio dessa socialização com o Núcleo que a formação dos profissionais que atuam nas escolas, nos sindicatos, nos órgãos de gestão educacional e na imprensa tem se configurado. Ação que, ao mesmo tempo, inicia os alunos no campo da pesquisa.

Além disso, os professores e os alunos participam de programas de formação e capacitação promovidos pelo Ministério da Educação, secretarias de educação estadual e municipais, sindicatos de trabalhadores da educação, unidades escolares. Atuam, igualmente, na organização dos espaços de discussão sobre a política educacional, como as Conferências de Educação municipais e estaduais, debates na universidade e no legislativo federal sobre os fundos de financiamento da educação, o Plano Nacional de Educação, entre outros.

Como uma das iniciativas em relação à divulgação do conhecimento produzido, está a edição do Jornal de Políticas Educacionais, desde 2007. Sua produção tem sido divulgada, também, pela publicação de artigos em outros periódicos e apresentação de trabalhos em encontros científicos nacionais e internacionais.

\section{Características da produção}

Depois de 10 anos, o levantamento acima realizado é, em primeiro lugar, um testemunho da proficuidade do trabalho feito em um grupo marcado pela diversidade. Esse grupo é composto por professores - com diferentes formações iniciais e experiências em pesquisa -; por alunos do ensino superior - iniciação científica, mestrandos e doutorandos -; e, por profissionais - professores, pedagogos, diretores, técnicos de secretarias e assessores e diretores de sindicatos - que atuam na área educacional e que tem como objetivo comum compreender como se realizam as politicas nesse campo, seus elementos, condicionantes e resultados.

Cumpre, portanto, com as expectativas de intensificação da produção acadêmica pela institucionalização do trabalho coletivo, presentes nos debates das associações de pesquisa, das agências de fomento e dos órgãos gestores da produção científica. Em que pesem iniciativas já existentes na década de 1980 (GATTI, 2005), a formação de grupos de pesquisa se configura como uma tendência na produção acadêmica brasileira, a partir da década de 1990, e busca superar a falta de consistência e continuidade que marca vários campos de pesquisa que tinham como base a produção individual. Assim, o levantamento dos trabalhos indica que o Núcleo

apresenta-se sob a forma de uma sucessão de projetos, desenvolvidos ao longo do tempo, que se constitui para atender a uma necessidade social, mediante um trabalho coletivo, institucionalizado e apoiado por uma ou mais agências de fomento, de um grupo de pessoas com vários níveis de qualificação e de experiência, que se organiza em torno de certas questões de determinada área do saber (SALLES \& BARREIRA, 2010, p.142).

O perfil dos integrantes, permanentes ou temporários, descrito anteriormente, mostra que o NUPE tem como uma das suas marcas a articulação entre universidade e outros setores que atuam em educação, o que tem ampliado a capacidade de formação de quadros não só para o próprio ensino superior, dado que muitos que passaram pelo NUPE atuam hoje nessa etapa de ensino, mas igualmente para outros espaços sociais.

Esse perfil é resultado da articulação entre as atividades de pesquisa, ensino e extensão. O NuPE não é exclusivamente um grupo de pesquisa, embora tenha nela sua atividade fundamental. Desde o 
início fez-se a opção pela realização de outras atividades que promovessem a discussão dos resultados e da experiência de investigação com os alunos de graduação e pós-graduação. Além disso, temos tomado como interlocutores os profissionais que atuam nas unidades escolares e nos órgãos de gestão, considerando a premissa de que essa interlocução vivifica o processo de investigação.

Esses profissionais têm a oportunidade de participar das pesquisas e/ou reuniões abertas para divulgação e discussão dos resultados promovidos, mensalmente, a partir de 2012. O acesso ao conhecimento elaborado no ensino superior deixa de estar vinculado estritamente à matrícula como aluno da UFPR, o que era um mecanismo de restrição desse acesso. Com isso, essas atividades têm se convertido em mecanismos de democratização de acesso à universidade como locus de produção social.

A articulação com outros núcleos de pesquisa e outras universidades também tem sido uma das características do trabalho, bem como a participação nas associações nacionais e regionais de pesquisadores, como a Associação Nacional de Pós-Graduação e Pesquisa em Educação (ANPED) e a Associação Nacional de Política e Administração da Educação (ANPAE). As pesquisas do NuPE estabelecem interlocução com aquelas realizadas em outros âmbitos, quer pela participação direta nas equipes, quer pela organização de reuniões de intercâmbio. Quebra-se, portanto, o isolamento e a endogenia que marcava, sob muitos aspectos, a produção no campo, e, ao mesmo tempo, com o caráter dependente da produção em relação aos centros considerados de excelência.

A natureza coletiva do trabalho tem possibilitado concorrer aos editais das agências de fomento, que, por sua vez se revertem no fortalecimento do NUPE. As pesquisas com financiamento, que apresentam a forma usual no Núcleo, permitem maior alcance e profundidade no recorte dos objetos de pesquisa, aquisição de equipamentos que operam com grandes bancos de dados, coleta de informações que ultrapassam o âmbito local e incluem por meio de bolsas, alunos e profissionais de fora da universidade.

Outra característica tem sido a articulação interna das pequenas equipes e das pesquisas individuais nas pesquisas de maior âmbito. Assim, ao mesmo tempo são realizadas pesquisas sobre temas específicos, como gestão, carreira docente, financiamento da educação etc. e outras em que esses aspectos vêm sendo articulados em torno da problemática da efetividade das políticas e da democratização da educação. Se considerarmos que os resultados alcançados pelas ações e pelos programas governamentais dependem das relações que se estabelecem entre eles, a possibilidade de estabelecer essas relações no processo de investigação, sem perder a perspectiva de aprofundamento dos diferentes aspectos, são um ganho qualitativo importante.

Observa-se que as temáticas ampliaram o foco das pesquisas, por exemplo, questões como o financiamento passam a se articular com outros temas como de qualidade e de efetividade da política.

Outra característica importante do trabalho do NuPE é a integração dos alunos de Iniciação Científica e da Pós-Graduação com grupos de pesquisas. Isso tem oportunizado ganhos na qualidade dos trabalhos pela socialização dos aportes teóricos e maior fôlego na coleta e organização dos dados, inclusive daqueles resultantes dos levantamentos nacionais realizados pelos respectivos órgãos federais (por exemplo, IBGE, Ministério da Fazenda, INEP).

A formação de pesquisadores tem sido um dos objetivos mais importantes do trabalho, considerando que para os menos experientes, ou iniciantes, é fundamental para sua formação, pois não se aprende a pesquisar, não se desenvolvem habilidades de investigador apenas lendo manuais. Essa aprendizagem processa-se por interlocuções, interfaces, participações fecundas em grupos de trabalho, em redes que se criam, na vivência e convivência com pesquisadores mais maduros (GATTI, 2005, p.124).

Os alunos têm disponíveis equipamentos capazes de operar grandes bancos de dados, dentro das instalações do Núcleo. Com isso rompeu-se o isolamento característico, do corpo discente o que culminou em qualidade e maior divulgação de resultados. Os resultados oferecidos permitiram aos alunos - com menos tempo para o desenvolvimento de suas pesquisas -, uma abrangência maior sobre suas temáticas. 
Além disso, a cooperação no campo metodológico tem ampliado a capacidade técnica individual e grupal. Consideramos, portanto, que

o processo de elaboração de teses, uma vez ocorrendo no interior de um grupo de pesquisa, adquire mais consistência, podendo tornar a atividade de orientação mais proveitosa e menos desgastante para professores e alunos. Além do clima estimulante, devido ao constante intercâmbio de informações, conhecimentos e ideias, adquire-se a consciência do valor da crítica enquanto atividade imprescindível à produção do conhecimento (SALLES \& BARREIRA, 2010, p.142).

Como projeto em construção pretendemos estreitar às relações das universidades estrangeiras com o Núcleo, internacionalizando o processo de investigação. Possibilitando, assim, a ampliação do escopo de pesquisa - que se iniciou com estudos mais locais, analisando políticas desenvolvidas pelo estado e por municípios paranaenses -, articulando-as à política nacional, avançando para estudos que comparam efetividade no Brasil, como é o caso da segunda pesquisa vinculada ao Observatório da Educação (Qualidade no ensino fundamental: uma leitura das condições de efetividade dos sistemas estaduais e municipais de ensino a partir de indicadores de financiamento, condições de oferta e resultados escolares) e segue agora incluindo os estudos comparados de abrangência internacional.

\section{Dificuldades e desafios}

A criação do NuPE se insere no movimento de constituição e definição de um campo recente de pesquisa educacional: o de políticas. Como já abordado, o próprio campo da pesquisa na área de educação está em processo de constituição. Discute-se desde quais são seus objetos de pesquisa quanto às questões metodológicas e teóricas. Maria Malta Campos (2009) aponta as fragilidades de um campo que adquiriu, ao longo da sua história, uma concepção pragmática, de fornecimento imediato de respostas aos problemas apontados pela mídia e pelos gestores públicos, o que tem dado a esse campo de investigação contornos de fragilidade. A autora enfatiza a posição de Charlot (2006) de que somos fracos no campo epistemológicos, com uma saturação de discursos já instalados que parte do senso comum sobre educação, dificultado ainda mais a consolidação da investigação.

Embora o NUPE esteja consolidado como um grupo de pesquisa que por uma década tem mantido e ampliado sua produção, em termos de resultados de pesquisa, sua divulgação e formação de novos pesquisadores, adensar teórica e metodologicamente esse trabalho é, ainda, um desafio que se impõe.

Há muito a ser feito na aquisição de competência para operação dos grandes bancos de dados. A maior parte dos pesquisadores hoje presentes no Núcleo faz parte de uma geração que foi alijada do acesso ao conhecimento estatístico, como resultado de um processo de negação, num primeiro momento, da pesquisa quantitativa, sem a qual é impossível entender a dinâmica das politicas públicas que, pela sua natureza, abarcam uma perspectiva analítica macrossocial.

Além disso, o desafio tem sido de dialogar com campos diversos do conhecimento. A ciência política, a sociologia, a economia, a estatística, entro outras, tem sido disciplinas de necessária interlocução, desafiando a equipe. Esse movimento coloca duas exigências de continuidade e aprofundamento: integrar pesquisadores de outros campos, ampliando a natureza interdisciplinar do grupo; aprofundar teoricamente e epistemologicamente os referenciais empregados nas pesquisas.

Essa última integra-se à dinâmica presente na área de investigação em políticas educacionais, da qual a criação da Rede Latinoamericana de Estudios Epistemológicos em Política Educativa se evidência. Essa discussão deve adquirir prioridade como condição de maior aprofundamento do campo e, portanto, das atividades do NuPE, no sentido de superar o que tem sido apontado como fragilidade da pesquisa em educação.

Enfim, cabe ressaltar a importância que se apresenta (e o desafio de manter crescentemente) a disponibilidade pessoal dos pesquisadores envolvidos para, no esforço de superar as tendências 
históricas e renovadas de competição entre os pesquisadores, compartilhar conhecimentos, experiências, expectativas. A solidariedade presente no grupo é condição sine qua non da sua permanência e da qualidade dos seus trabalhos.

\section{Referências Bibliográficas}

CAMPOS, M. M. Para que serve a pesquisa em educação? Cad. Pesqui., São Paulo, v. 39, n. 136, abr. 2009. CHARLOT, B. A Pesquisa educacional entre conhecimentos, políticas e práticas: especificidades e desafios de uma área de saber. Revista Brasileira de Educação, v.11, n.31, jan./abr. 2006.

GATTI, B. A. Formação de grupos e redes de intercâmbio em pesquisa educacional: dialogia e qualidade. Rev. Bras. Educ., Rio de Janeiro, n. 30, dez. 2005.

SALLES, E. B.; BARREIRA, I. A. Formação da comunidade científica de enfermagem no Brasil. Texto contexto - enfermagem. Florianópolis, v. 19, n. 1, mar. 2010.

Recebido em setembro de 2012 Aprovado em novembro de 2012 